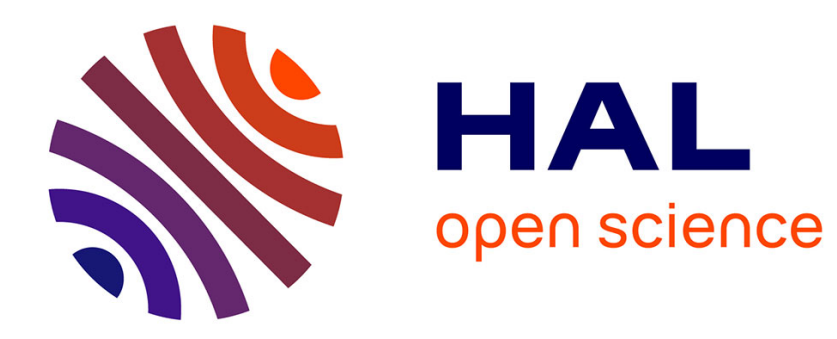

\title{
Encoding and maintaining reference in oral discourse.
}

Florence Canoz, Monique Vion

\section{To cite this version:}

Florence Canoz, Monique Vion. Encoding and maintaining reference in oral discourse.. International Journal of Psychology, 1994, 29 (5), pp.537-564. hal-00134165

\section{HAL Id: hal-00134165 https://hal.science/hal-00134165}

Submitted on 1 Mar 2007

HAL is a multi-disciplinary open access archive for the deposit and dissemination of scientific research documents, whether they are published or not. The documents may come from teaching and research institutions in France or abroad, or from public or private research centers.
L'archive ouverte pluridisciplinaire HAL, est destinée au dépôt et à la diffusion de documents scientifiques de niveau recherche, publiés ou non, émanant des établissements d'enseignement et de recherche français ou étrangers, des laboratoires publics ou privés. 


\title{
Encoding and Maintaining Reference in Oral Discourse
}

\author{
Florence Canoz and Monique Vion \\ CREPCO, Université de Provence, Aix-en-Provence, France
}

This study deals with information management and reference encoding modes in oral discourse production. Three potentially influential factors were the distance between the first occurrence of an item and its later occurrences, a topic change that takes the focus off that item, and the span of the conceptual information available for verbalization. French-speaking adult subjects were asked to tell stories from comic strips to a listener who was unfamiliar with them. The frames in each strip were presented simultaneously or in succession. Four versions were generated for each comic strip: a given version was either short (three frames) or long (eight frames), and either did or did not have a topic change. The results showed that the target character was usually marked as a given, regardless of the version. This was more often true, however, when the topic did not change. When the character was treated as a given, referent accessibility marking was dependent on (1) topic change alone when the frames were presented simultaneously, and (2) topic change and comic strip length when the frames were presented in succession. The discussion analyzes the results in terms of the allocation of cognitive resources to maintaining coreference and to assisting addressees in their processing.

Key words: production, oral discourse, incremental processing, coreference, collaborative process.

L'étude concerne trois determinants du mode de gestion de l'information et du maintien de la rdfdrence dans la production orale: la distance entre la premiere occurrence d'un élément et son occurrence ultérieure, lc changement (ou le non changement) de focus dont ce même élément peut faire l'objet et l'empan des informations conceptuellement disponibles pour être verbalisées. On a demandé a des sujets adultes francophones de raconter (pour un destinataire qui ne les connalt pas) des histoires présentées sousforme de bandes dessinées. Les vignettes composant chaque bande dessinée sont, ou bien présentées simultanément, ou bien présentées successivement. Une même bande dessinée peut prendre quatre formes différentes selon que, dans une version courte ( 3 vignettes) ou longue (8 vignettes), elle reste ou ne reste pas centrée sur les actions accomplies par un même personnage. L'analyse des résultats montre que: (1) Le personnage est majoritairement marqué comme connu quelle que soit la version. II l'est cependant davantage lorsqu'il a fait l'objet d'un focus maintenu. (2) Lorsque le personnage est marqué comme connu, le marquage de l'accessibilité de ce référent est: (a) exclusivement dépendant du focus lorsque les vignettes sont présentées simultanément; (b) dépendant du focus et de la longueur des histoires lorsque les vignettes sont présentées successivement. La 
discussion analyse ces résultats en termes de partage des capacités de traitement du locuteur entre les exigences d'établissement de la co-référence et celles d'aide à fournir au traitement réalisé par le destinataire.

\section{INTRODUCTION}

Co-operative speakers make sure that the listener can construct an accurate mental representation of the message they are attempting to transmit. To do so, they can rely on the addressee's knowledge and use deictic and linguistic devices to refer respectively to the utterance situation and to the previous statements in the discourse.

To put their messages into words, speakers can use the means offered by the natural language they speak. Among the linguistic devices at their disposal are those used to mark givenness or newness and to make anaphoric references to previously mentioned entities. Expressing and maintaining reference in discourse has been studied from a developmental perspective for various languages (for a critical review, see Hickmann, 1984; 1991), but the factors influencing referential system usage by adults have not been investigated nearly as much. The present study was designed to gain insight into these factors.

The system of markers available for expressing references in a given language is considered by Ariel $(1988 ; 1990 ; 1991)$ as a "grammaticalization" of cognitive factors. In her theory of accessibility, Ariel stresses the tight link between givenness and definiteness. She hypothesizes that the entities the listener needs to construct a mental representation differ in their level of activation in memory. General knowledge is less accessible than immediate percepts of the surrounding environment, or information that has just been verbalized (Clark \& Marshall, 1981). The speaker codes the degree of accessibility of each entity linguistically according to the assumed availability of that entity to the listener. In other words, each time a reference is made to a previously introduced entity, the expression chosen by the speaker to indicate its degree of accessibility is used by the listener to retrieve the antecedent.

Based on a comparison of accessibility coding in various languages, Ariel (1988) devised a universal scale that establishes a correspondence

between the state of activation in memory and accessibility coding. The items on this scale range from referential 
TABLE 1

Ranking of Accessibility Markers (from Ariel, 1991)

LOW ACCESSIBILITY

Full name

Full name + Modifier

Long definite description

Short definite description

Last name

First name

Distal demonstrative (+ Modifier)

Proximal demonstrative (+ Modifier)

Stressed pronouns + Gesture

Unstressed pronouns

Zeros

HIGH ACCESSIBILITY

markers of high accessibility (such as ellipsis and pronouns, which are void of semantic information) to expressions of low accessibility (such as proper nouns and definite descriptions, which convey lexical information). Table 1 presents these markers in ascending order of accessibility.

The French language uses some of the markers and forms shown in Table 1. Their function is to indicate when an expression must or can be interpreted as having the same referent as another. These markers have been studied by examining the linguistic and cognitive constraints governing the reference patterns or "chains" they form (see Charolles, 1987). For a given language, a hierarchy can be defined by establishing a correspondence between the markers (necessarily discrete) and the degree of accessibility (a continuous variable). Unlike the English devices (see Gemsbacher's ranking, 1989a; 1989b; based on the Explicitness Principle), the French markers have not been examined from this point of view. For lack of a finely graduated scale, a very rough correspondence can be established for French based on the three accessibility categories (low, intermediate, and high) defined by Ariel (1988) in her initial research based on Clark and Marshall's (1981) context typology. At the lowest level of the scale are indefinite noun phrases ("A terrorist commando blew up ... " ). Then come markers of low accessibility such as proper names ("Napoleon was born, in Corsica"). These are followed by complete definite descriptions (i.e. intrinsically defined: "The president of France declared yesterday ...") and incomplete definite descriptions (extrinsically defined: "The president told the press ..."). Demonstrative noun phrases ("This table is 
shaky") express intermediate accessibility, and third-person personal pronouns and ellipsis mark high accessibility.

As discourse is produced, a large number of entities are activated. For each one, the listener must store an instantaneous but labile item in working memory. Due to the limited capacity of working memory, the question that arises-first raised by Chafe (1974; 1976)-is: How long do items remain activated in the listener's memory and thus, how long can they be treated as a given by the speaker?

Several empirical studies on comprehension have shown that the establishment of coreference during text reading depends on various factors (Garnham, 1987; Gernsbacher, 1989b; Morrow, 1985; Yekovich \& Walker, 1978) including the distance between the antecedent and the anaphor (Clark \& Sengul, 1979; Clifton \& Ferreira, 1987; Daneman \& Carpenter, 1980; Ehrlich, 1983; Ehrlich \& Rayner, 1983; Frederiksen, 1981; Lesgold, Roth, \& Curtis, 1979; Whitehead, 1982), potential competition between antecedents (Clancy, 1980), the salience of the antecedent as a discourse topic (Fletcher, 1984; Garrod \& Sanford, 1982; Purkiss, 1978, cited by Sanford \& Garrod, 1981;' Yekovich, Walker, \& Blackman, 1979), and the unit of the reference framework (sentence, paragraph) encompassing the antecedent and the anaphor (Anderson, Garrod, \& Sanford, 1983; Li \& Thompson, 1979). These factors have not been studied as extensively from the producer's end of the process, especially not in oral discourse production by adults.

The present study focuses on two potential factors affecting the choices made by a speaker to mark the accessibility of a previously mentioned referent: distance and salience.

Another factor that may affect the use of referent accessibility markers as discourse is being produced is the organization of the mental representation underlying the verbalization. Speakers engaging in verbal production may or may not have a general plan for organizing the parts of their discourse. Although such a plan probably exists when a narrative is about to be related, direct commentary of a football game, for example, may well not have an underlying plan. In the traditional conception of language production, which has focused essentially on the conditions of written text production, it is assumed that conceptualization, formulation, and articulation are strictly ordered in time. Opposed to this serial conception is an incremental one, which is better at accounting for oral production. Speakers often start verbalizing when they have prepared conceptually only a part of what they are going to say. In this case, the conceptual structure that leads to the production of statements should be viewed as a cumulative and ordered sequence of bits of content (Kempen \& Hoenkamp, 1982, 1987; Leveit, 1989). As soon as a conceptual bit is available, it is transmitted to the subprocess in charge of formulation, which in turn attempts to 
translate it into part of a statement, which, in its turn, will be transformed by the next subprocess in order to be articulated. During this time, processing continues on other syntactic and conceptual bits, such that the three production subprocesses are executed in parallel. In an incremental model of production, the conceptualization subprocess is not syntactically competent. Moreover, each bit is processed independently of the bits to come, that is, with very little looking ahead. In this framework, the process of marking the accessibility of referents can be seen as tightly linked to the span of the conceptual bits available for verbalization.

The aim of the present study was to look at how this span interacts with distance and salience to determine what accessibility markers are chosen. These three dimensions were operationalized in the following manner. In line with past research on discourse comprehension, distance was not defined as a simple physical distance, measured in number of words or statements. It was measured here for discourse production in terms of the number of events to relate. The salience of an entity can depend on various properties, whose effects are often mixed (Karmiloff-Smith, 1981; McGann \& Schwartz, 1988). Certain properties are nonlinguistic (visual characteristics like size, for example), others are linguistic (position in the utterance), and still others are both (agentivity, repeated occurrence of an entity). Salience was defined here as the continuous presence of the same character throughout a series of events. Conceptual span was controlled by showing the speaker the events either all at once or one after the other (i.e. the next event was not available when the preceding one was verbalized).

\section{METHOD}

\section{Subjects}

The experiment was run on 32 adult subjects. They were male or female nativeFrench-speaking psychology students between the ages of 20 and 25 .

\section{Task}

The subjects were asked to relate stories to someone who "didn't know them." The stories were in comic strip format with no captions or balloons. For half of the subjects, the entire story was presented on a single page, and the instructions told them to "read" the entire comic strip and prepare to tell it immediately afterwards. For the other half, the comic strip was presented frame by frame on a computer screen. The instructions said to tell the story as the frames appeared (self-paced display). In both cases, the subjects were asked to report the events as accurately as possible (i.e. to include each event while avoiding excess detail). The listener was simply asked to listen carefully. 


\section{NO TOPIC CHANGE}

short
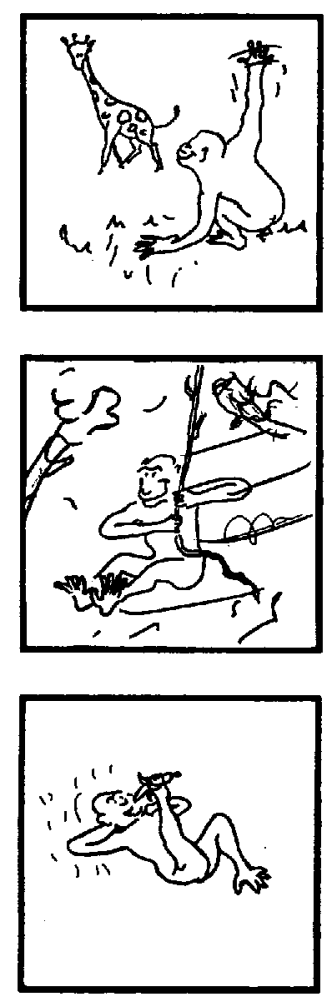

long
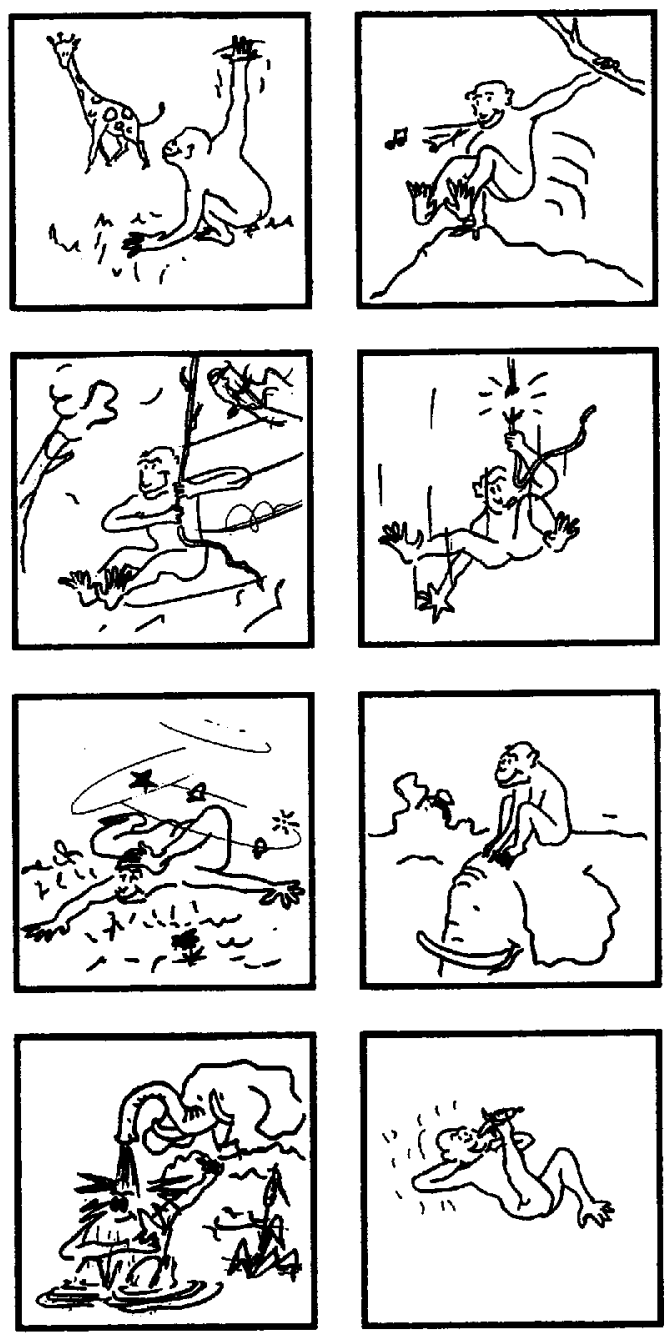

V2

V1 


\section{TOPIC CHANGE}

\section{short}
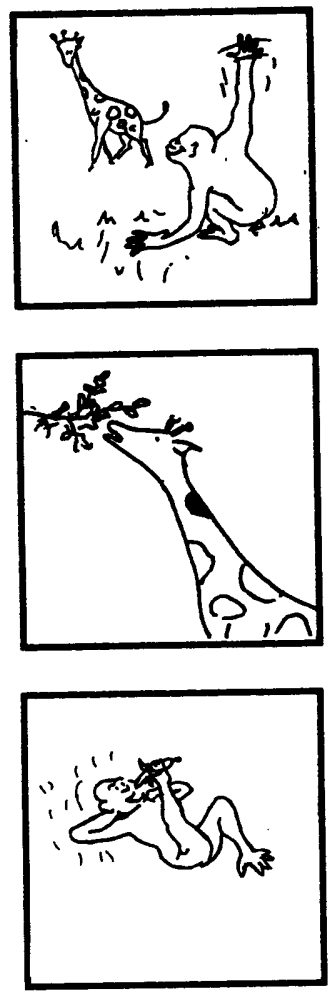

long
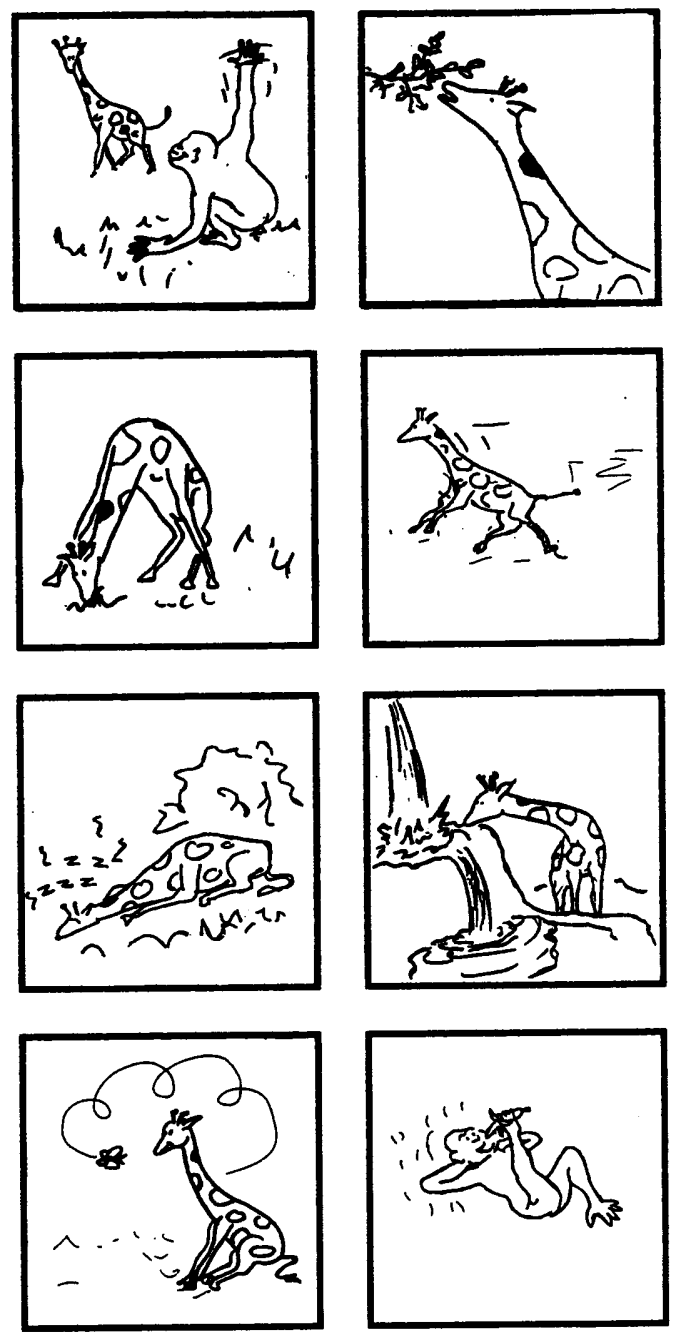

V4

V3

\section{Material}

The first frame in each comic strip depicted two characters (e.g. a monkey and a giraffe). The subsequent frames showed only one of the two characters. Examples of the material used for the monkey/giraffe story are shown on pages 
542 and 543. Four versions were generated for each story by crossing two factors. Topic and Length, each with two modalities. These factors operationalize the notions of salience and distance, respectively.

In versions $\mathrm{Vi}$ and $\mathrm{V} 2$, the same character was shown for the rest of the story (frame 2 on). In this case, there was no topic change (Tn) (the monkey, for example, was the topic throughout the story). In versions V3 and V4, the same character was shown until the last frame, and then the other character reappeared. In this case, there was a topic change (Tc) (all frames showed the giraffe except the last frame, which showed the monkey). Hereafter, the character in the last frame will be called the target character. The target character was the same in all four versions (in our example, the monkey). For each modality of the topic factor, the story was either short (three frames; V2 and V4) or long (eight frames; Vi and V3).

For all versions, story continuity was achieved by repeating the setting (for example, "the brush" in the monkey/giraffe story; see description of material in Appendix 2) and by continuously showing one of the characters depicted in the first frame. In versions Vi, V2, and V3 a thematic subject (Karmiloff-Smith, 1981) was generated after the first frame by the repeated presence of the same character. Version V3 (long) also introduced a change in topic with the reappearance of the other character in the last frame. Version V4 (short) could not generate a thematic subject. In this version, if the event presented in the first frame suggested a specific role (that of agent, for example), one of the characters could be granted that role by default. Indeed, Gernsbacher (for a review, see Gernsbacher, 1990) pointed out the importance of the first character mentioned in subsequent cognitive processing (in comprehension, the first items mentioned appear to be the basis for the construction of a coherent mental representation of the information). The set of events used as first-frame events in our material were such that, taken as a whole, they could not induce such an effect systematically (see Appendix 2 for a description of the first-frame events and an analysis of the corresponding verbalizations). Note finally that the decision to define the distance as the number of events to be related meant that the framework of the story in the long versions was loose. In most cases, the character that appeared in the middle frames engaged in several different activities, which were more or less independent and chronologically interchangeable (1).

Frame 2 The giraffe is nibbling on the leaves of a tree.

Frame 3 The giraffe is nibbling on the grass.

Frame 4 The giraffe is running.

Frame 5 The giraffe is sleeping.

Frame 6 The giraffe is drinking at a waterfall.

Frame 7 The giraffe sees a butterfly.

If any of the activities were interdependent, the link never encompassed all six frames (2).

Frame 2 The cat sees a ball of yarn.

Frame 3 The cat gets caught in the yarn. 
Frame 4 The cat pounces on a mouse.

Frame 5 The cat backs up against a wall.

Frame 6 The cat is playing with a feather pillow.

Frame 7 The cat is eating in a dish.

The experimental material included a total of 32 test comic strips (8 character pairs $X 4$ versions) and 3 filler comic strips interspersed with the others. The fillers also consisted of either three or eight frames (see description in Appendix 1) but only featured one character.

\section{Design}

A given subject saw eight test comic strips (one of the four versions for each pair of characters) and three fillers (presented after each set of two test strips). Given that there were twice as many character pairs as versions, a subject saw each version twice but with different characters. The presentation order of the 32 test comic strips is shown in Table 2.

\begin{tabular}{cccccccc}
\multicolumn{8}{c}{ TABLE 2 } \\
\multicolumn{8}{c}{ Design } \\
\hline 1 & 2 & 3 & Character Pairs \\
V1 & V1 & V4 & V4 & V3 & V3 & V2 & V2 \\
V2 & V2 & V1 & V1 & V4 & V4 & V3 & V3 \\
V3 & V3 & V2 & V2 & V1 & V1 & V4 & V4 \\
V4 & V4 & V3 & V3 & V2 & V2 & V5 & V5 \\
\hline
\end{tabular}

The Presentation mode $(P)$ factor had two modalities: simultaneous (Si) and successive (Su). It was used to operationalize the notion of conceptual span. A story presentation order was randomly assigned to each subject in each group (four subjects per row in Table 2).

\section{Procedure}

Three persons were present in the room where the experiment was held: the subject (the speaker), the experimenter, and the listener. For the simultaneous presentation mode, the speaker was given the following instructions.

I would like to introduce you to $X$ (listener's name), to whom you are going to tell some comic strip stones I'll give you. You are going to "read" the first story, as you would any comic strip, except that it has no words. "Read" the whole thing. When you think you understand the story, tell it to X, who doesn't know it. Try to tell the story as 
accurately as possible, without giving too many details. Proceed frame by frame as if you were reading it. Then we'll go on to the next story.

The experimenter presented the first comic strip. The speaker studied it and then told it to the listener. When the speaker had finished, the experimenter took the comic strip away and presented the next one. For the successive presentation mode, the instructions were the same as above except for the following modification:

... You are going to see each comic strip frame by frame. Start by clicking with the computer mouse on the screen button labelled "Turn page". The first picture will appear. Tell what happens to X, who doesn't know the story. When you're finished, click on the button to go on to the next picture. There will be a message indicating the end of each story. This will warn you that a new story is about to begin. To start the next comic strip, click on the button.

Between each comic strip, the experimenter reminded the subject that he! she was supposed to tell the story one frame at a time.

\section{Predictions}

The first reference to the target character pertained to the event in the first frame. The experiment was designed to study how the accessibility marking of that character varies as a function of salience, distance, and conceptual span (measured via the topic, length, and presentation mode factors). Our predictions concern the first mention of that character when it appeared in the last frame.

In French, an indefinite expression is used to mark a brand new piece of information. The chances of finding indefinite expressions in this experiment should therefore be nearly nil, since even in the case where the story focused on the other character, the target was never totally new (due to its occurrence in the first frame). However, if accessibility marking is a function of the (assumed) lifetime in the (listener's) memory of the item in question, it may happen that the target character is marked with an indefinite article when (1) the topic changes, (2) the story is long, and! or (3) the frames are presented one by one. Indeed, in all of these cases, the speaker may assume that the previous givenness of the referent has weakened, and may thus use a linguistic form that reintroduces the character as new.

A definite noun phrase can be employed to mark a previously mentioned referent overtly. A definite article is thus appropriate in all of the cases studied here. Because definite noun phrases serve to remind the listener explicitly of the target character, the chances of finding one are greater, as already seen, when (1) the topic changes, (2) the story is long, and (3) the frames are presented one at a time. 
Third-person, definite pronouns (subject or object), being highaccessibility markers, should be employed when the topic does not change. Thus, the chances that they will be used to refer to the target character are greater when

(1) the topic does not change in a long story, and (2) the entire comic strip is presented at once. Note that the same predictions hold true for ellipsis, even though it is subject to more specific constraints (ellipsis in French mainly occurs on the subject of the sentence).

\section{RESULTS}

\section{References to the Target Character}

\section{Overall Results}

For each presentation mode and the last frame in each comic strip, 128 verbalizations were collected ( 16 subjects $X 4$ versions $X 2$ comic strips). Table 3 gives the number of times each type of marker occurred in the first reference to the target character on the last frame. Figure 1 presents these same results by presentation mode.

Note that there were only a few cases where the target character was not mentioned at all (Si 3.13\% and Su 9.98\%). This occurred mainly on stories 4 and 7 , where instead of talking about the target character, certain subjects spoke of another referent (e.g. "And suddenly the balloon blew away and the crying started," or "We can see a flying saucer moving away"). When the target character was mentioned, it was usually designated with a definite pronoun (subject or object) or a definite expression (e.g. "the monkey," "her husband," "that woman"). As predicted, the less frequent use of an indefinite article to refer to the target character (Si 8.59 and Su 14.84) can be explained by the fact that it was always present in the first frame of each story, and thus could never be considered as truly new. The few rare cases of ellipsis ( 8 in all, for 256 responses, e.g. ". . and falls asleep and goes beddy-bye") were only found (as predicted) when the topic did not change.

The following analyses concern the three most frequent types of markers observed (definite pronouns, definite expressions, and indefinite 


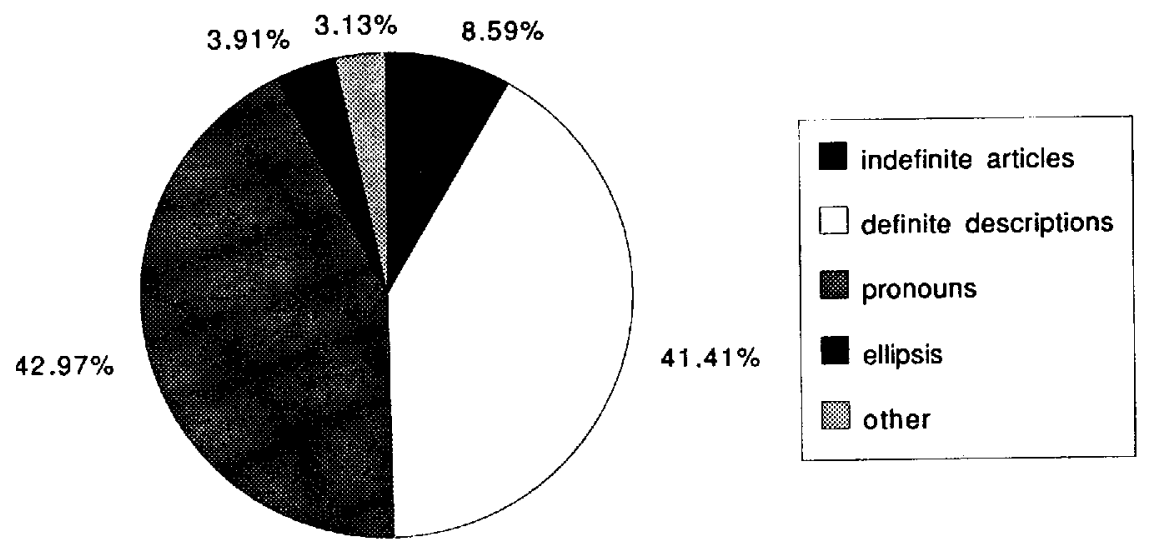

Successive $(N=128)$

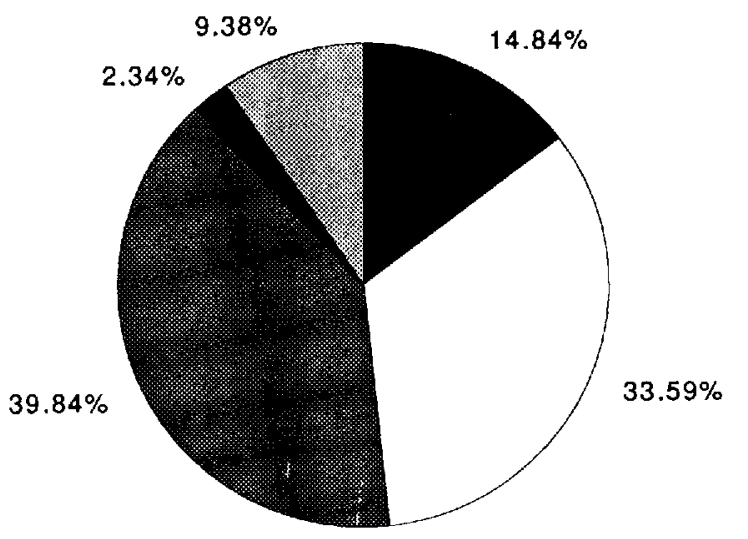

FIG. 1 Last frame: Marking of target accessibility, by presentation mode.

8.59 and Su 14.84) can be explained by the fact that it was always present in the first frame of each story, and thus could never be considered as truly new. The few rare cases of ellipsis ( 8 in all, for 256 responses, e.g. ". . and falls asleep and goes beddy-bye") were only found (as predicted) when the topic did not change.

The following analyses concern the three most frequent types of markers observed (definite pronouns, definite expressions, and indefinite 
TABLE 3

Last Frame: Marking of Target Accessibility (Overall Results)

\begin{tabular}{|c|c|c|c|c|c|c|c|}
\hline & & $\begin{array}{l}\text { Indefinite } \\
\text { Articles }\end{array}$ & $\begin{array}{l}\text { Definite } \\
\text { Descriptions }\end{array}$ & Pronouns & Ellipsis & Other & Total \\
\hline \multicolumn{8}{|l|}{ Simultaneous } \\
\hline No topic & long & 0 & 4 & 26 & 2 & 0 & 32 \\
\hline & short & 1 & 4 & 23 & 3 & 1 & 32 \\
\hline Topic change & long & 7 & 22 & 2 & 0 & 1 & 32 \\
\hline & short & 3 & 23 & 4 & 0 & 2 & 32 \\
\hline Successive & & & & & & & \\
\hline $\begin{array}{l}\text { No topic } \\
\text { change }\end{array}$ & long & 1 & 4 & 23 & 3 & 1 & 32 \\
\hline & short & 6 & 7 & 17 & 0 & 2 & 32 \\
\hline Topic change & long & 9 & 12 & 5 & 0 & 6 & 32 \\
\hline & short & 3 & 20 & 6 & 0 & 3 & 32 \\
\hline Total & & 30 & 96 & 106 & 8 & 16 & 256 \\
\hline
\end{tabular}

articles). Three analyses of variance were computed on all results pooled to study the effects of presentation mode, topic, and length on the number of occurrences of each type of marker (the possible values for each dependent variable ranged between $\mathrm{O}$ and 2), with presentation mode as a between factor and topic and length as within factors. For each presentation mode, three analyses of variance were computed for the same dependent variables, with topic and length as within factors.

\section{Simultaneous Presentation}

The only significant effects observed for this presentation mode concerned the topic factor.

Pronouns. Most of the definite pronouns were employed to refer to the target character when the topic did not change (Th 1.69 vs. Tc 0.19

(topic effect: $1 \mathrm{J1} 15]=89-18, \mathrm{P}<0.00001$ ). This result is consistent with our predictions. Definite pronouns function as markers of information that is highly accessible in memory.

Definite Expressions. Definite expressions were more frequent when the topic changed (Th 0.25 vs. Tc 1.40) (topic effect: FJ1,15] = 38.383, $\mathrm{P}<000001$ ). In this case, definite expressions were used to refer overtly to the target character again, thus bringing it back into the picture while still acknowledging the fact that it was not brand new. 


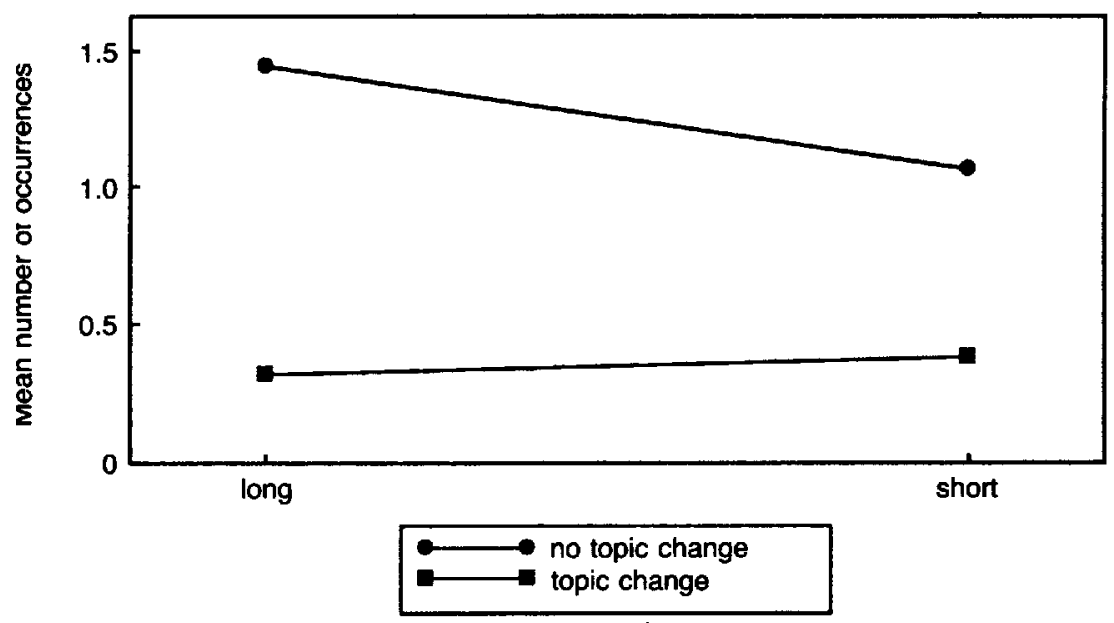

FIG. 2 Pronouns: Interaction between topic and length in successive presentation.

Indefinite Articles. The target character was sometimes designated with an indefinite article, which is inappropriate. This rarely happened when the topic did not change (0.03), but was more frequent when it did (0.31) (topic effect: Fr1,15] $=7.642, \mathrm{P}<0.0145)$. In the latter case, although the target character was not totally new, it was marked as such by the speaker.

Thus, when the speaker could mentally organize all the information before verbalization, the marking of the accessibility of the target character depended solely upon its salience. As a whole, the target was marked by a pronoun when it was present in all depicted events, and by a definite expression (and sometimes an indefinite one) when it did not reappear until the last frame.

\section{Successive Presentation}

The results for this presentation mode were more complex.

Pronouns. As seen earlier, pronouns were used extensively when the topic did not change (Th 1.25 vs. Tc 0.34) (topic effect: F11,151=32.26, $\mathrm{P}<0.00001$ ). A tendency was also found, as can be seen in Fig. 2 ( $T X L$ interaction: F11,15] = 3.296, $P<0.08$ ). The rare (and incorrect) usage of a pronoun when the topic changed did not vary with story length. But when the topic did not change, a pronoun tended to be employed more often when the story was long (referent givenness increased and was marked as such, as predicted). Further analysis of the data using a $2 \times 2$ factorial design with comic strip as the random factor did not yield an interaction 


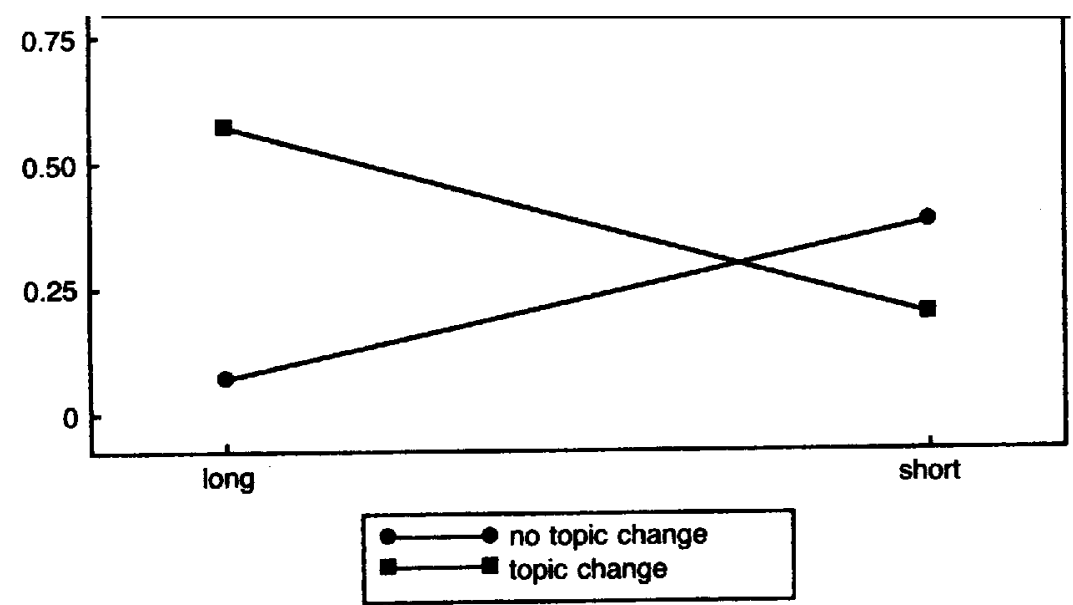

FIG. 3 Indefinite articles: Interaction between topic and length in successive presentation.

between topic and length. A length effect was noted, however $(F T 1,7]=11.667$; $P<0.0112$ ), which confirms the predicted increased use of pronouns to refer to the target character in long stories.

Definite Expressions. As in the preceding presentation mode, the use of definite expressions was greater when the topic changed (Th 0.34 vs. Tc 1.00) (topic effect: $F 1,15\}=15.07, P<0.0015$ ).

Indefinite Articles. Figure 3 shows the interaction between the topic and length factors ( $T \times L$ interaction: $F 1,15\}=8.442, P<0.0109)$. As in simultaneous presentation, indefinite articles were used when the target character was the topic throughout the story. However, these (inappropriate) occurrencs were more numerous in the short version than in the long one. Successive presentation made the event in each frame appear relatively independent. Having only three frames showing the same character (short version) does not seem to have been sufficient for the speaker to regard the comic strip as a story. In contrast, when the topic changed, indefinite articles were used more often in the long version. Thus, there was indeed a tendency for the indefinite article "a" to be used to reintroduce the target character as new whenever the two references to this character were far apart.

When the only means available to the speaker for constructing a mental representation of the information to be verbalized was the gradual accumulation of successive events, the marking of target character accessibility depended first on salience, then on distance. 


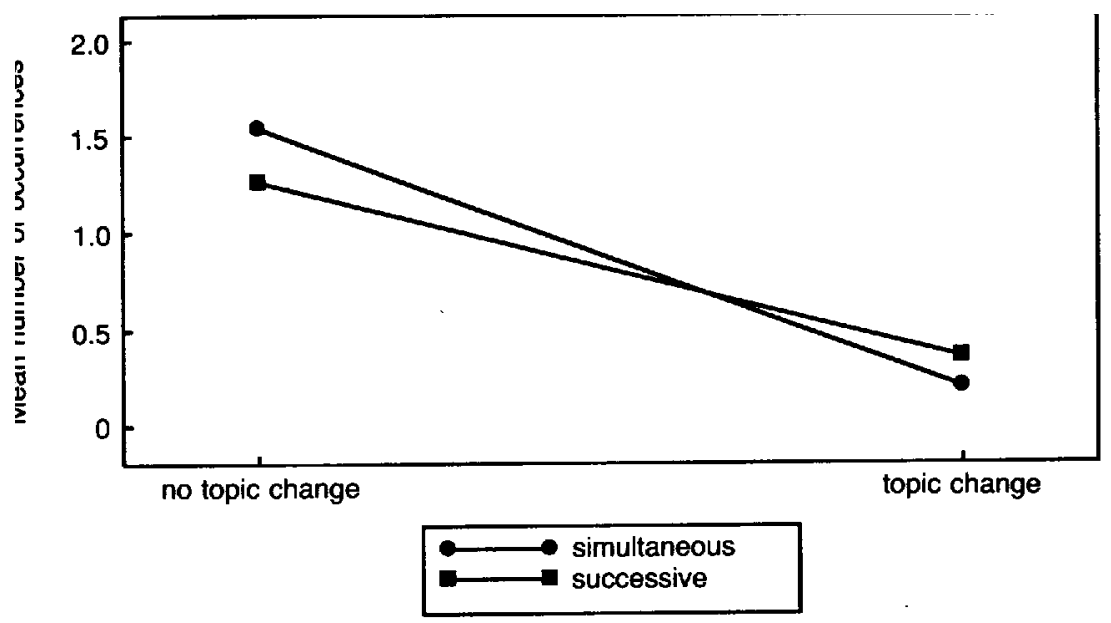

FIG. 4 Pronouns: Interaction between topic and presentation mode.

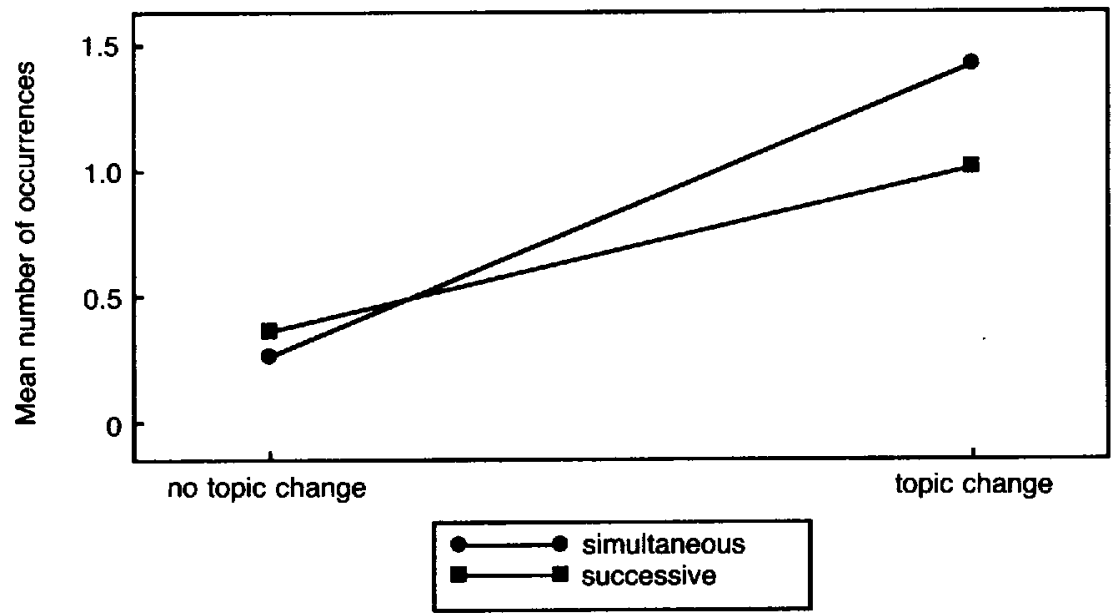

FIG.5 Definite expressions: Interaction between topic and presentation mode.

\section{Comparison of Presentation Modes}

For the pooled data analyses, significant effects of the topic factor were obtained again for pronouns $(\mathrm{F} 11,30]=110.769, \mathrm{P}<0.00001)$, definite expressions $(\mathrm{F} 11,30]=51.807, \mathrm{P}$ C 0.00001$)$, and indefinite articles $(\mathrm{fT} 1,30]=8.596, \mathrm{P} C 0.0064)$, along with an interaction between topic and length for indefinite articles $(F 11,301=10.492, P<$ $0.0029)$ and pronouns $(F 11,30]=4.0303, P<0.0467)$. These analyses also pointed out some variations in the salience effect as a function of the conceptual span.

Pronouns. When the topic did not change, pronouns in simultaneous presentation outnumbered those in successive presentation. The opposite occurred in the case of a topic change (PX T interaction: $F 11,30]=4.188, P<$ 
0.0496) (Fig. 4). Reanalysis of the data using comic strip as the random factor confirmed the earlier result $(\mathrm{P} X \mathrm{~T}$ interaction: $\mathrm{T11}, 71=10.500, \mathrm{P}<0.0142)$.

Definite Expressions. Definite expressions were used more extensively with topic changes when presentation was simultaneous rather than successive. In this case, the target character seems to have lost its givenness to a greater extent, due to the fact that information was acquired event by event. The opposing effect was obtained for no topic change $(\mathrm{P} X \mathrm{~T}$ interaction: $\mathrm{FJ1}, 30]=$ 3.943, $P<0.0563$ ) (Fig. 5).

Thus, the way the speaker marked the accessibility of the target character, primarily a function of its salience as thematic subject, was also dependent upon whether or not the salience became apparent immediately or gradually as more and more frames were seen. To gain insight into how the span of the information available for verbalization influences the speaker's choice of markers for expressing referent accessibility, the verbalizations produced for the long stories (excluding the last frame) were analyzed.

\section{Coreferencing in Long Stories}

The events depicted in the six middle frames of the long stories all pertained to the same character (either the target character or the other character), so we can look at how references to this main character (thematic subject of frames 2 to 7 ) were made for each presentation mode.

The transcriptions of the 128 verbalizations ( 4 stories $X 16$ subjects $X$ 2 presentation modes) were segmented by referring to the events in the frames and considering prosodic cues such as intonation (continuative vs. terminal intonation) and pauses. For each segmented verbalization, the reference chain was diagrammed as a series of states (each diagram consisted of six states, one per frame). Four types of markers could be found in each state of the diagram (indefinite expressions, definite expressions, pronouns, and ellipsis). For each verbalization, a path was drawn between the initial state (frame 2) and the final state (frame 7). This path would account for potential changes in the coreference devices used for the main character as verbalization progressed.

Four types of "paths" could be observed. A path could be continuous or discontinuous. It was considered to be discontinuous (3) when, for at least one frame, the statement(s) made did not pertain to the main character (indicated by an asterisk).

Frame 2 (whistling monkey). Then the monkey is happy. He whistles.

Frame 3 (swinging monkey). He swings from vine to vine.

Frame 4 (falling monkey). And then the vine breaks. ${ }^{*}$

Frame 5( dizzy monkey). And he falls to the ground and he looks hurt. Frame 6 (monkey on elephant). And then he forgets about the vines and he gets on an elephant's back. 
Frame 7 (monkey being showered). They get to a pond, I don't know, and so the elephant gives him a shower with its trunk. (3)

A continuous path could be rectilinear, exhibit a progression, or include one or more regressions. A path was called rectilinear (4) when markers of equivalent accessibility were used to refer to the main character in each frame. Note that, regardless of the presentation mode, rectilinear marking was only achieved with pronouns, as in the example below.

Frame 2 (flying saucer ET). He gets in the flying saucer.

Frame 3 (Saturn ET). And he obviously wants to go to the other planet. Frame 4 (meteorite ET). Then some meteorites almost crash into him. Frame 5 (landing ET). So he has to make an emergency landing.

Frame 6 (planet ET). Finally he takes off again.

Frame 7 (comet ET). And he runs into some more meteorites. (4)

A path was said to exhibit a progression (5) when the character was referred to first with a low-accessibility marker and then with highaccessibility markers.

Frame 2 (yawning soldier). The soldier is obviously tired.

Frame 3 (cat soldier). He is awakened from his daydreaming by a cat meowing on a wall.

Frame 4 (sighing soldier). He sighs, glad it's a cat.

Frame 5 (owl soldier). He is surprised again by an owl who is hooting.

Frame 6 (church soldier). Then, by bells ringing from afar in the church.

Frame 7 (gesturing soldier). And then uh makes a vulgar gesture.(5)

A path was considered to exhibit one or more regressions (6) when the markers used to refer to the main character alternated between different degrees of accessibility.

Frame 2 (dog grandmother). In the second picture the grandmother stops and the baby carriage is behind her and she pets a cat. 
Simultaneous $(\mathbf{N}=64)$
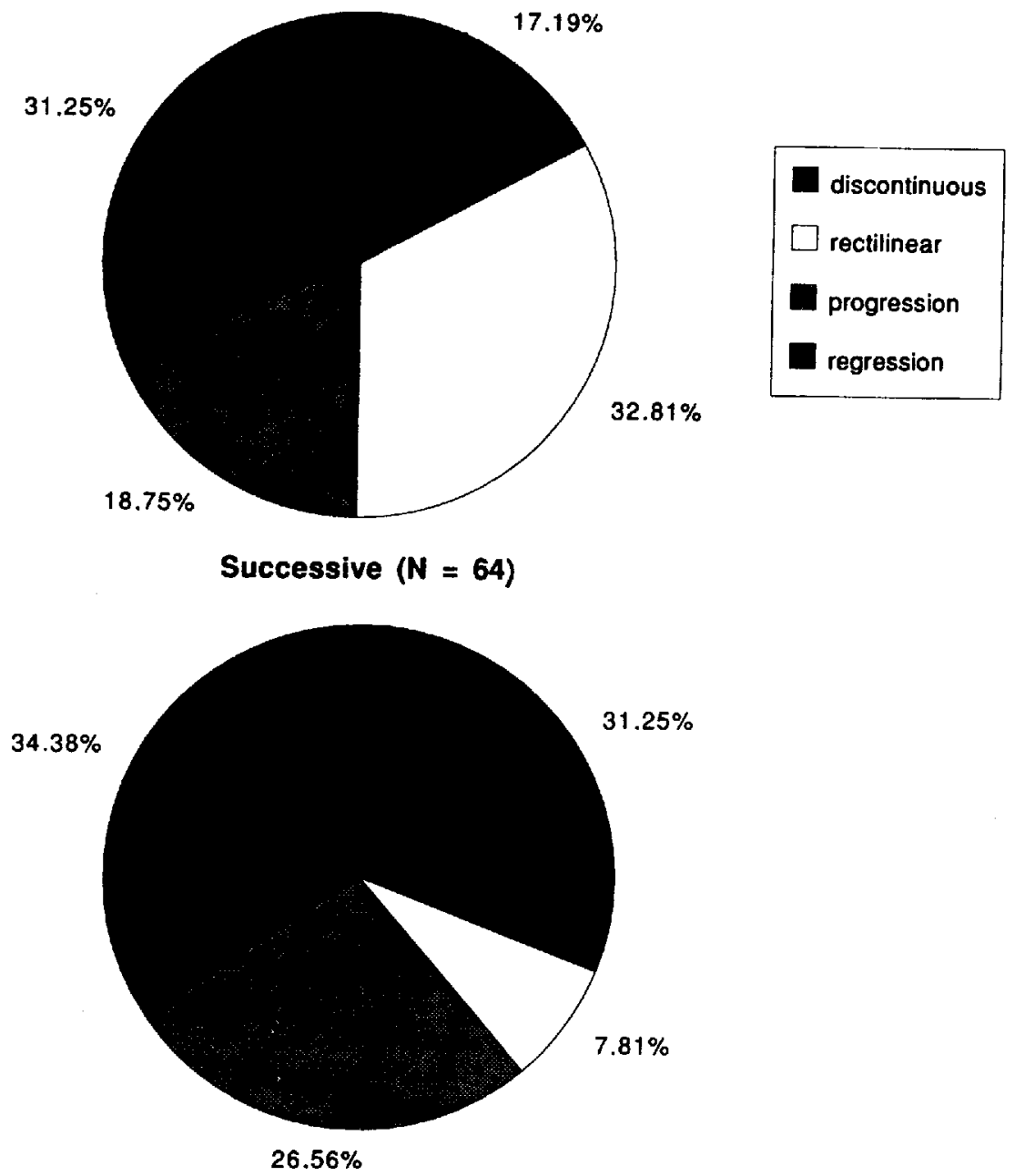

FIG. 6 Long stories: Proportion of each type of production, by presentation mode (for frame 2 to 7 ).

Frame 3 (leek grandmother). In the third picture she is shopping. It looks like she is buying leeks.

Frame $4 \quad$ (skateboard grandmother). In the fourth she is still walking along with her baby carriage and there's a young kid going by with a skateboard.

Frame 5 (dreaming grandmother). In the fifth you have the grandmother dreaming about skateboarding.

Frame 6 (child grandmother). In the sixth she apparently asks him to loan her his skateboard.

Frame 7 (skateboarding grandmother). In the seventh she is skateboarding.

(6) 
For all verbalizations pooled, the proportion of each of the four major types of paths was found to vary significantly across presentation modes ( $X 2=13.42$; $P<0.01)$.

Note (Fig. 6) that the rectilinear path, which was the prevailing type of verbalization in simultaneous presentation $(32.81 \%)$, was the most infrequent in the successive condition (7.81\%). In simultaneous presentation, the number of pronouns in the reference chain ranged from its minimum of six, to three times that length (7).

Frame 2 (dog grandmother). Well she keeps on walking and this time she comes across a dog she stops she lets go of her baby carriage and she, she pets it for a few minutes.

Frame 3 (leek grandmother). Uh she goes and buys some vegetables she chooses leeks.

Frame 4 (skateboard grandmother). She continues with her shopping she comes across a boy on a skateboard.

Frame 5 (dreaming grandmother). And she, she gets the idea that she too would like to try the skateboard.

Frame 6 (child grandmother). Finally she stops the little boy and asks him if she can try.

Frame 7 (skateboarding grandmother). She tries and she really has fun.

(7)

The existence of referential chains consisting exclusively of pronouns can be interpreted here as in Combettes' (1986) study. For this author (p. 81), using a pronoun is the "normal," unmarked way of expressing the antecedent/substitute link: "As long as the speaker uses a pronoun, it means that, for him, things are happening normally we might say." The author agrees with Karmiloff-Smith's (1981) position that the use of a pronoun in a referential chain is an indication that there is no other thematic subject to introduce. The extremely low frequency observed of this type of path in successive presentation can be viewed as an indication of the fact that, in this presentation mode, the subjects had no guarantee that the thematic subject would be maintained (which they did when the entire comic strip was seen at once). The decrease in the number of rectilinear paths in successive presentation led to unequal increases in the other three types of paths.

The number of discontinuous paths (8) rose from $17.19 \%$ in simultaneous presentation to $31.25 \%$ in successive presentation.

Frame 2 (yawning soldier). And apparently the soldier, he is tired, he yawns.

Frame 3(cat soldier). And at the place he's guarding there's a cat who starts meowing and the soldier is surprised because the cat starts meowing.

Frame 4 (sighing soldier). He's even afraid because he felt threatened, there's a sigh in the picture.

Frame 5 (owl soldier). Now it's a bird. * 
Frame 6 (church soldier). And now again he's afraid and then he uses his weapon and he shoots.

Frame 7 (gesturing soldier). So then he looks irritated he makes a vulgar gesture. (8)

As in simultaneous presentation, and to an equal extent, there were paths with progressions like the ones observed earlier, where the chain was rectilinear after the first verbalization (second frame) (9).

Frame 2 (tree giraffe). The giraffe is eating leaves off a branch.

Frame 3 (nibbling giraffe). Then she starts grazing on the grass.

Frame 4 (running giraffe). And she runs away.

Frame 5 (sleeping giraffe). And after running for a long time she falls into a deep sleep.

Frame 6 (drinking giraffe). Then she goes to drink at a small waterfall.

Frame 7 (butterfly giraffe). She sits down and watches a butterfly flying around. (9)

The increase in the number of paths with progression (Si $18.75 \%$ vs. Su $26.56 \%$ ) was essentially due to the rise in the number of paths exhibiting a slow transition to higher accessibility marking (10). Apparently, these speakers needed more events proving the main character's status as thematic subject before they could use markers of high accessibility.

Frame 2 (tree giraffe). The giraffe is eating leaves off a tree.

Frame 3 (grazing giraffe). Here it's the giraffe who's grazing.

Frame 4 (running giraffe). Here the same giraffe is running.

Frame 5 (sleeping giraffe). Here she's sleeping.

Frame 6 (drinking giraffe). And then here she's drinking.

Frame 7 (butterfly giraffe). Here she's looking at a butterfly passing

by.

(10)

More paths with regression(s) (Si 31.25 vs. Su 34.38) were found here than in simultaneous presentation (11), which indeed points out the impact of presentation mode on marker usage during production.

Frame 2 (dog grandmother). Well now here it's the same woman so there's the baby carriage, you can see the baby carriage on the far left, she is petting a dog, she is a little bent over.

Frame 3 (leek grandmother). Here it's still that woman so she is probably at the market since there are fruit and vegetable stands in front of her and she is holding a leek in her hands, finally she looks at a leek. Frame 4 (skateboard grandmother). So here that woman is walking along again with her baby carriage and in front of her there's a little boy who is skateboarding. 
Frame 5 (dreaming grandmother). So here it looks like that woman is thinking, she's thinking again about that little boy she just saw on the skateboard, then there's balloon with the same picture.

Frame 6 (child grandmother). Then that woman is talking to the little boy who is holding his skateboard in his hands.

Frame 7 (skateboarding grandmother). And here in this picture, she must have asked him in the last picture to try his skateboard and here we can see her on the little boy's skateboard.

In these cases, a definite expression was used to indicate that the same character was in every frame, but the information that was conceptually available with each new frame was the chosen framework, within which the speaker employed markers of higher and higher accessibility to refer to the same character.

\section{DISCUSSION}

The interactive dimension of language production and comprehension has been the focus of a growing number of empirical and theoretical studies over the past 10 years in the cognitive sciences. The transmission of a mental representation has been viewed as both the purpose and the product of verbal activity. At the reception end, discourse-being endowed with a procedural component-conveys a variety of linguistically encoded instructions that give receivers an idea of how they should assemble the elements being transmitted (Caron, 1984; Garrod \& Sanford, 1982). At the production end, the speaker or writer uses a certain number of devices to help the receiver make the correct interpretation of what is being stated (Clark \& Wilkes-Gibbs, 1986; Hajicova, 1991). The indications provided by the speaker (or writer) are such that the receivers' attention is attracted to certain elements of their own knowledge, and new relationships are established among those elements through the creation of links with newly acquired items (Sperber \& Wilson, 1986). But we still have much to learn about the interspeaker trade-off needed to reduce the cost of processing while ensuring successful communication (Vion, 1992).

Due to limitations in human attentional and memory capacities, the cognitive psychology of discourse processes has stressed the incremental nature of speech processing at both ends of communication, thus pointing out the labile, non-exhaustive and ever-modifiable nature of the output of discourse processing. At the reception end, the gradual construction of a mental model seems to be achieved by avoiding anything that would complicate or burden processing. Thus, at the very same time as the conditions of written discourse productionwhere linguistic context plays an important role-are such that a stable and invariable spatial-temporal framework and a complete and autonomous reference universe are constructed, it appears that the link between pronouns and the corresponding antecedents in a written text is not always encoded (Oakhill, Garnham, \& Vonk, 1989). Similarly, at the emission end of communication, 
textual "deformations" (with respect to the above norm) are observed in referential device usage, even in spontaneous writing, showing that within a given production, enunciation is not always based in a systematic way on the same frame of reference (Reichler-B6guelin, 1988).

The results of the present experiment on oral discourse production are consistent with the findings in the linguistic and psycholinguistic literature on the importance of salience. They also illustrate the incremental nature of discourse processing. When the same character occurred repeatedly across events, a greater number of high-accessibility markers were used to refer to him in the last event (third-person, personal pronouns). When he was only present in the first and last events, low-accessibility markers (definite expressions), or even definite expressions marking newness were used. These results also show that the linguistic choices made by speakers to indicate the availability of a referent to the listener depend in the end on the conceptual processing done by the speaker before beginning to speak. When all the events to be related are available at the onset, the linguistic choices made depend exclusively on whether or not the same referent is present across events (salience). In this case, speakers can apprehend what is being described and directly transform. their own representations into a narrative form (Trabasso \& Nickels, 1992). They can choose a referent as the theme and quickly grant it a marker of high accessibility in their verbalizations. In this case, oral production takes place under conditions similar to those encountered in written production (Rubin, 1987) and story-telling.

When not all the events to be related are available, the speakers' linguistic choices still appear to depend on the salience factor, but they also vary with the number of events to relate (distance). In this case, (1) information about the salience of a referent can only be acquired gradually (seeing several frames was the only way a speaker could be sure of his/her interpretation), and (2) as a complement to this, the givenness of a referent tends to weaken if it is not updated in the events that follow. The tradeoff for establishing the link between the content of the frames is an increase in the processing cost for speakers. Their attention is focused on each event as it occurs, and it is not possible to determine whether the relationships being established between the referents are valid. Comparisons can only be made based on the memory of previous events. The overall "picture" of production is quite different here. For example, the central part of the long stories contained more of the French presentative forms beginning with "C'est" (It's) and "II y a" (There is/are), used to describe or label the components of the events (4df $301=-2.947$; $\mathrm{P}<0.006$ ). The production conditions were such that the current event (span of newly acquired information) tended to become the chosen framework, within which the speaker used markers of increasingly high accessibility to refer to the same referent, and increasingly low accessibility to refer to the other referents.

Fulfilling the costly requirements of establishing coreference appears to be the speaker's primary concern, such that helping the listener comprehend the message becomes a secondary matter. Due to the ongoing nature of oral 
discourse, speakers can only manage their production according to a system of priorities and trade-offs, which hinge on the current importance of each process.

\section{REFERENCES}

Anderson, A., Garrod, S.C., \& Sanford, A.J. (1983). The accessibility of pronominalantecedents as a function of episode shifts in narrative texts. Quarterly Journal ofPsychology, 35a, 427-440.

Ariel, M. (1988). Referring and accessibility. Journal of Linguistics, 24(I), 65-87.

Ariel, M. (1990). Accessing NP antecedents. London: Routledge.

Ariel, M. (1991). The function of accessibility in a theory of grammar. Journal of Pragmatics, 16, 443-463.

Caron, J. (1984). Les opérateurs discursifs comme instructions de traitement. Verbum, VII, 149-163.

Chafe, W.L. (1974). Language and consciousness. Language, 50, 111-133.

Chafe, W.L. (1976). Givenness, contrastiveness, subjects, topics and point of view. In C. Li (Ed.), Subject and topic (pp. 25-56). New York: Academic Press.

Charolles, M. (1987). Contraintes pesant sur la configuration des chaînes de référence comportant un nom propre. Travaux du Centre de Recherches Sémiologiques, 53, 29-55.

Clancy, P.M. (1980). Referential choice in English and Japanese narrative discourse. In W.L.

Chafe (Ed.), The pear stories, Vol 3, in R.O. Freedle (Ed.), Advances in discourse processes (pp. 127-202). Norwood: Ablex.

Clark, H.H., \& Marshall, C.R. (1981). Definite reference and mutual knowledge. In A.K. Joshi, B.L. Webber, \& I.A. Sag (Eds.), Elements of discourse understanding (pp. 10-63). Cambridge: Cambridge University Press.

Clark, H.H., \& Sengul, C.J. (1979). In search of referents for noun phrases and pronouns. Memory and Cognition, 7, 35-41.

Clark, H.H., \& Wilkes-Gibbs, D. (1986). Referring as a collaborative process. Cognition, 22,1-39.

Clifton, C., \& Ferreira, F. (1987). Discourse structure and anaphora: Some experimental results. In M. Coltheart (Ed.), A ttention and performance XII. The psychology of reading. London: Lawrence Erlbaum Associates Ltd.

Combettes, B. (1986). Introduction et reprise des éléments d'un texte. Pratiques, 49, 69-M.

Daneman, M., \& Carpenter, P.A. (1980). Individual differences in working memory and reading. Journal of Verbal Learning and Verbal Behaviour, 19, 450-466.

Ehrlich, K. (1983). Eye movements in pronoun assignment: A study of sentence integration. In K. Rayner (Ed.), Eye movements in reading: Perceptual and language processes (pp. 253-268). New York: Academic Press. 
Ehrlich, K., \& Rayner, K. (1983). Pronoun assignment and semantic integration during reading: Eye movements and immediacy of processing. Journal of Verbal Learning and Verbal Behaviour, 22, 75-87.

Fletcher, R.C. (1984). Markedness and topic continuity in discourse processing. Journal of Verbal Learning and Verbal Behaviour, 23, 487-493.

Frederiksen, J.R. (1981). Understanding anaphora: Rules used by readers in assigning pronominal referents. (Tech. Rep. no. 3.4462). Cambridge, Mass.: Bolt Beranek and Newman Inc. (ERIC Document Reproduction Service No ED 205 930).

Garnham, A. (1987). Understanding anaphora. In A.W. Ellis (Ed.), Progress in the psychology of language, Vol. 3, London: Lawrence Erlbaum Associates Ltd.

Garrod, S.C., \& Sanford, A.J. (1982). The mental representation of discourse in a focused memory system: Implications for the interpretation of anaphoric noun phrases. Journal of Semantics, 1, 21-41.

Gernsbacher, M.A. (1989a). Cognitive processes and mechanisms in comprehension. The structure building framework. In G.H. Bower (Ed.), The psychology of learning and motivation. New York: Academic Press.

Gernsbacher, M.A. (1989b). Mechanisms that improve referential access. Cognition, 32, 99-156.

Gernsbacher, M.A. (1990). Language comprehension as structure building. Hillsdale, NJ: Lawrence Erlbaum Associates Inc.

Hajicova, E. (1991). Topic-focus articulation and coreference in models of discourse production. Journal of Pragmatics, 16, 157-166.

Hickmann, M. (1984). Fonctions et contexte dans le développement du langage. In M. Deleau (Ed.), Langage et communication à l'âge préscolaire (pp. 2758). Rennes: Presses Universitaires de Rennes.

Hickmann, M. (1991). The development of discourse cohesion: Some functional and cross- linguistic issues. In G. Pi6raut-Le Bonniec \& M. Dolitsky (Eds.), Language base ...Discourse bases. Amsterdam/Philadelphia: John Benjamins Publishing Co.

Karmiloff-Smith, A. (1981). The grammatical marking of thematic structure in the development of language production. In W. Deutch (Ed.), The child's construction of language (pp. 121-147). London: Academic Press.

Kempen, G., \& Hoenkamp, E., (1982). Incremental sentence generation: Implications for the structure of a syntactic processor. In J. Horecky (Ed.), Proceedings of the Ninth international Conference on Computational Linguistics. Amsterdam: North Holland.

Kempen, G., \& Hoenkamp, E. (1987). An incremental procedural grammar for sentence formulation. Cognitive Science, li, 201-258.

Lesgold, A., Roth, S., \& Curtis, M. (1979). Foregrounding effects in discourse comprehension. Journal of Verbal Learning and Verbal Behaviour, /8, 291308.

Levelt, W.J.M. (1989). Speaking. Cambridge, Mass.: MIT Press. 
Li, C.N., \& Thompson, S.A. (1979). Third-person pronouns and zero anaphora in Chinese discourse. In T. Givon (Ed.), Syntax and semantics, I2(pp. 311335). New York: Academic Press.

McGann, W., \& Schwartz, A. (1988). Main character in children's narratives. Linguistics, 26, 215-233.

Morrow, D.G. (1985). Prominent characters and events organize narrative understanding. Journal of Memory and Language, 24, 304-319.

Oakhill, J., Garnham, A., \& Vonk, W. (1989). The on-line construction of discourse models. Language and Cognitive Processes, 4, 263-286.

Reichier-Béguelin, M.J. (1988). Norme et textualité. In G. Shoeni, J.P. Bronckart, \& P. Perrenoud (Eds.), La langue française est-elle gouvernable? Normes et activités langagières (pp. 185-216). Neuchâtel: Delachaux \& Nietsld.

Rubin, D.L. (1987). Divergence and convergence between oral and written communication. Topics in Language Disorders, 7 (4), 1-8.

Sanford, A.J., \& Garrod, S.C. (1981). Understanding written language. Chichester: Wiley.

Sperber, D., \& Wilson, D. (1986). Relevance: Communication and cognition. Oxford: Blackwell.

Trabasso, T., \& Nickels, M. (1992). The development of goals plans of action in the narration of a picture story. Discourse Processes, 15, 249-275.

Vion, M. (1992). Le traitement de la parole échangée. Unpublished manuscript. Université de Provence: Aix en Provence.

Whitehead, E. L. (1982). Distance and foregrounding effects on pronoun interpretation. Paper presented to the Experimental Psychology Society, Cambridge, 25-26 March.

Yekovich, FR., \& Walker, C.H. (1978). Identifying and using referents in sentence comprehension. Journal of Verbal Learning and Verbal Behaviour, 17, 265277.

Yekovich, F.R., Walker, C.H., \& Blackman, H.S. (1979). The role ofpresupposed and focal information in integrating sentences. Journal of Verbal Learning and Verbal Behaviour, 18, 535-548.

\section{APPENDIX 1}

\section{Topics of the Eight Test Comic Strips}

The noun in italics indicates the character present in the last frame of the comic strip (the target)

1. A cat and a dog in an apa23ment

2. A soldier and an officer in front of the barracks

3. A monkey and a giraffe in the brush

4. A child and a balloon man in a park

5. A man and a woman in their apartment 
6. A grandmother and a punk in the street

7. A martian and a robot on a planet

8. A gardener and a sailor in the countryside

Topics of the Three Filler Comic Strips

a. A computer scientist solves a problem

b. A vagabond in the city

c. A cat at the beach

\section{APPENDIX 2}

\section{Description of the Event Depicted in Frame 1}

1. A dog is chasing a cat

2. An officer shows a shelter to a soldier

3. A monkey says hello to a giraffe

4. A child points to the man's balloons

5. Two people are in bed, one is yawning, the other is about to get up

6. Two people walking towards each other are about to cross paths

7. Two martians are facing each other

8. Two people wave at each other

Analysis of the references to the characters in the 256 first-frame verbalizations showed that the 2 characters were named separately in $71.49 \%$ of the cases; they were named together $25.78 \%$ of the time (e.g. "two people," "a couple," "some inhabitants"); only 1 was mentioned in the remaining $2.73 \%$ of the cases. The number of instances in each of these 3 categories was independent of presentation mode $(\mathrm{X} 22=2.10, \mathrm{~ns})$.

For each story, the following table presents the number of references in each of these categories. When the two characters were mentioned separately, the order in which they were mentioned was distinguished.

We can see by examining this distribution that the designations varied across comic strips, and that there were certain prevailing tendencies concerning which one was mentioned first. A preferred order was found for stories 1,2 , and 3 . This order was linked to differences in the salience of the characters acting in the depicted events (the agent was mentioned first). Stories 4 and 6 did not have a preferred order. In comic strips 5 and 8 , the characters were generally mentioned together. In story 7 , the characters were either mentioned together or in a preferred order (living, nonliving). 


\begin{tabular}{|c|c|c|}
\hline Story & $\mathrm{PI}$ & PS \\
\hline \multicolumn{3}{|l|}{ Story I } \\
\hline Both & 0 & 0 \\
\hline cat-dog & 4 & 3 \\
\hline dog-cat & 12 & 13 \\
\hline only one & 0 & 0 \\
\hline \multicolumn{3}{|l|}{ Story2 } \\
\hline Both & 2 & 4 \\
\hline soldier-officier & 4 & 5 \\
\hline officier-soldier & 10 & 7 \\
\hline only one & 0 & 0 \\
\hline \multicolumn{3}{|l|}{ Story 3} \\
\hline Both & 0 & 1 \\
\hline monkey-giraffe & 14 & 13 \\
\hline giraffe-monkey & 2 & 1 \\
\hline only one & 0 & 1 \\
\hline \multicolumn{3}{|l|}{ Story 4} \\
\hline Both & 0 & 1 \\
\hline child-balloon man & 8 & 6 \\
\hline balloon man-child & 5 & 7 \\
\hline only one & 3 & 2 \\
\hline \multicolumn{3}{|l|}{ Story 5} \\
\hline Both & 10 & 12 \\
\hline man-woman & 5 & 4 \\
\hline woman-man & 1 & 0 \\
\hline only one & 0 & 0 \\
\hline \multicolumn{3}{|l|}{ Story 6} \\
\hline both & 0 & 2 \\
\hline grd mother-punk & 8 & 8 \\
\hline punk-grd mother & 8 & 6 \\
\hline only one & 0 & 0 \\
\hline \multicolumn{3}{|l|}{ Story 7} \\
\hline both & 6 & 8 \\
\hline ET-robot & 8 & 4 \\
\hline robot-ET & 1 & 4 \\
\hline only one & 1 & 0 \\
\hline Story 8 & & \\
\hline
\end{tabular}




\begin{tabular}{lll}
\hline both & 10 & 10 \\
gardener-sailor & 5 & 6 \\
sailor-gardener & 1 & 0 \\
only one & 0 & 0 \\
& & \\
\hline
\end{tabular}

